\title{
PENGEMBANGAN MULTIMEDIA INTERAKTIF BERBASIS MOBILE PADA BAHASA INGGRIS
}

\author{
Fatimah Dwi Yuliana, Susilaningsih, Zainul Abidin \\ Teknologi Pendidikan, Fakultas Ilmu Pendidikan, Universitas Negeri Malang. \\ Jl. Semarang No.5, Malang, 65145, Indonesia. \\ Yuliana123547@gmail.com
}

Article History

Received: 17 November 2020, Accepted: 26 Maret 2021, Published: 20 Februari 2022

\begin{abstract}
Abstrak
Tujuan pengembangan ini adalah untuk menghasilkan produk program aplikasi multimedia interaktif berbasis mobile yang layak digunakan pada pembelajaran bahasa Inggris SMA kelas XI. Produk multimedia interaktif berbasis mobile dapat digunakan sebagai suplemen pelengkap dalam proses pembelajaran bahasa Inggris. Program aplikasi multimedia interaktif dikemas kedalam bentuk mobile learning dengan pemanfaatan menggunakan mobile device atau smartphone. Rincian konten materi dan desain interface dirancang dengan sistem user friendly agar mudah dipahami dan digunakan oleh pengguna. Terdapat latihan - latihan soal mandiri yang menarik. Keunggulan multimedia interaktif berbasis mobile dapat digunakan secara mandiri tanpa terbatas waktu dan ruang. Dapat digunakan secara klasikal dengan panduan guru. Prosedur pengembangan multimedia interaktif bebasis mobile menggunakan model Lee \& Owens, 2004. Tanggapan dari ahli media dan ahli materi terhadap produk multimedia interaktif mendapatkan respon positif. Uji coba pemanfaatan produk dilakukan terhadap siswa SMA kelas XI. Secara keseluruhan produk multimedia interaktif berbasis mobile pada bahasa Inggris layak digunakan dalam pembelajaran.
\end{abstract}

Kata kunci: Multimedia Interaktif; Bahasa Inggris; Mobile Learning

\begin{abstract}
The purpose of this development is to produce a mobile-based interactive multimedia application program product that is eligible for use in high school English learning class XI. Mobile-based interactive multimedia products can be used as complementary supplements in the English learning process. Interactive multimedia application program is packaged into the form of mobile learning with the use of mobile devices or smartphones. The details of the material content and interface design are designed with a user friendly system to be easily understood and used by the user. There are interesting self-contained exercises. The advantages of mobile-based interactive multimedia can be used independently without limited time and space. Can be used clasikall with teacher's guide. Mobile-free interactive multimedia development procedure using Lee \&Owens model, 2004. Responses from media experts and material experts to interactive multimedia products received a positive response. Product utilization trials were conducted on grade XI high school students. Overall interactive multimedia products based on English are worth using in learning
\end{abstract}

Keyword: Interactive Multimedia; English Subject; Mobile Learning 


\section{PENDAHULUAN}

Kemajuan dan perkembangan teknologi informasi semakin berkembang pesat. Salah satu dampak dari kemajuan dan perkembangan teknologi informasi saat ini adalah digunakannya teknologi dalam dunia pendidikan sebagai media alat bantu dalam pembelajaran (Sanaky, 2013). Pada proses pembelajaran media digunakan sebagai penghubung antara sumber belajar kepada anak didik (Sihkabuden, 2015). Media pembelajaran dinyatakan sebagai media grafis, photografis, atau elektronis, yang bisa dipakai untuk mengungkap, memproses, dan menata kembali informasi secara visual atau verbal (Azhar \& Ardi, 2008).

Menurut National Education Asociation media merupakan suatu bentuk komunikasi baik secara tercetak ataupun melalui audio visual dan peralatannya. Dalam dunia pendidikan media dapat dimanfaatkan utnuk menyampaikan pesan kepada penerima sehingga bisa merangsang kemapuan berpikir, keinginan, perasaan, dan ketertarikan anak didik yang menjadikan terjadinya proses belajar (Arief, 2009). Kontribusi media sebagai penyampaian pesan dapat menyangga keberhasilan pembelajaran menjadi lebih interaktif lagi.

Pada penerapan K13 (kurikulum 2013) yang mengharuskan pola pembelajaran lebih interaktif, lebih tertuju pada siswa (student center), lebih menggunakan pola pembelajaran jejaring, dan pola pembelajaran berlandaskan multimedia menjadikan penerpan media pembelajaran sangat dibutuhkan bukan hanya sebagai alat bantu dalam pembelajaran tetapi jadi suplemen tambahan dalam pembelajaran, sehingga pembelajaran pun tidak berpusat pada guru saja (teacher center).

Berdasarkan observasi yang telah diselenggarakan di SMA Ahmad Yani Ngebruk diketahui kondisi lingkungan belajar di SMA Ahmad Yani Ngebruk sangat kondusif dan mendukung adanya pemanfaatan media. Terlihat dari fasilitas sekolah yang menyediakan laboratorium dan beberapa media pembelajaran seperti LCD proyektor namun penggunaanya dirasa masih kurang optimal, disisi lain sekolah juga memperkenangkan anak didik membawa smartphone akan tetapi fungsi dari smartphone tersebut tidak dapat dipergunakan pada saat jam pembelajaran.

Berdasarkan hasil wawancara terhadap guru kelas XI SMA Ahmad Yani Ngebruk dapat diidentifikasikan bahwa pelaksanaannya masih banyak pendidik menerapkan metode konvensional dengan memberikan ceramah dan penugasan terutama pada pembelajaran teori. Hal ini disebabkan karena belum adanya alat pembelajaran dengan menerapkan perangkat teknologi computer ataupun perangkat teknologi mobile. Dari pembelajaran yang telah terjadi, pembelajaran bahasa Inggris belum tersedia media yang digunakan dengan baik. Pembelajaran bahasa Inggris merupakan jawaban alami dari kebutuhan komunikasi secara aktif maupun peka(Littlewood \& William, 1984).

Proses pembelajaran bahasa Inggris tidak selalu dilaksanakan didalam laboratorium bahasa, dikarenakan letak laboratorium dengan ruangan kelas berbeda tempat sehingga jika digunakannya ruangan laboratorium bahasa anak didik diharuskan moving class yang menyebabkan terbuangnya jam pembelajaran. Oleh sebab itu pendidik lebih sering melaksanakan pembelajaran di kelas saja dengan menggunakan media berbentuk cetak seperti modul dan LCD proyektor untuk menapilkan slide presentasi yang hanya bersifat satu arah sehingga proses interaktivitas anak didik kurang optimal.

Anak didik hanya melihat dan mendengarkan guru melalui tayangan pada LCD proyektor yang di control oleh pendidik sehingga menjadikan pembelajaran hanya berorientasi pada guru saja (teacher center). Mengingat beberapa kemampuan setiap individu dalam menerima dan memproses sebuah informasi berbeda-beda dapat menyebabkan kurang idealnya materi di terima anak didik terlebih materi itu hanya di sampaikan melalui satu arah dan hanya menggunakan metode konvensional tanpa dipadukan dengan adanya media. Disisi lain perjumpaan tatap muka antara guru 
dan anak didik dirasa kurang sehingga dibutuhkan sebuah media pembelajaran yang efisien tanpa dibatasi oleh ruang dan waktu.

Perpaduan antara media dengan pembelajaran bisa mengatasi beberapa permasalahan atau kekurangan pada pembelajaran, terutama pada pembelajaran yang menggunakan metode konvensional. Perpaduan media dengan pembelajaran bisa menjadikan pembelajaran lebih inovatif lagi serta interakif, sehingga mempermudah penyampaian dan penyerapan sebuah penjelasan saat diberikan.

Dari berbagai jenis alat bantu pembelajaran yang bisa digunakan, multimedia dirasa cukup mampu mengakomodasi kebutuhan dalam penyajian informasi. Multimedia ialah kumpulan dari beberapa media akan menjadikan pembelajaran lebih inovatif lagi serta interaktif. Hal tersebut menjadikan multimedia interaktif dimanfaatkan sebagai alternatif pembelajaran.

Berdasarkan persoalan yang dipaparkan diatas, combinasi antara multimedia interaktif dengan mobile learning dirasa cocok untuk mengatasi permasalahan pembelajaran. Penggunaan multimedia interaktif memanfaatkan mobile device atau smartphone bisa digunakan secara individu maupun berkelompok. Multimedia adalah kombinasi beberapa elemen gambar, teks, grafik, audio,animasi, dan video menjadikan multimedia mendapat nilai lebih dibandikan media lainya (Darmawan, 2014). Pengetahuan seseorang paling banyak diperoleh secara visual, jumlah informasi diperoleh seseorang melalui indra penglihatan (visual) dengan koposisi $75 \%$, indra pendengaran (auditori) 13\%, indra sentuhan dan perabaan 6\%, indra penciuman dan perasa 6\% (Husamah, 2013).

Pemanfaatan teknologi mobile pada pendidikan disebut dengan mobile learning (Georgiev et al., 2004). Mobile learning merupakan pembelajaran menggunakan perangkat teknologi (device) bergerak, mobile merupakan perangkat kecil yang bisa dibawa kemana saja dan kapanpun disetiap waktu (Mamat \& Azmat, 2013). M-learning mencakup karakteristik dari e-learning bagian konten multimedia dan komunikasi anak didik lain, m-learning mempunyai ciri khas dalam hal fleksibilitas, waktu, dan tempat. Manfaat dari pembelajaran mobile learning menjadikan anak didik lebih mandiri, mengatasi keterbatasan indra, ruang dan waktu (Rahardjo, 2019).

Pengembangan multimedia interaktif berbasis mobile sebagai media yang digunakan dalam pembelajaran mempunyai beberapa keuntungan diantaranya bersifat portability (portabilitas), menghemat tempat, kemampuan dan kemudahan dalam konektifiktas jaringan, instan tidak perlu proses booting,dapat digunakan kapanpun dan dimana saja, dan long life battery tergantung pada konektifitas kabel.

Multimedia interaktif berbasis mobile akan memuat beberapa penjelasan berkaitan dengan materi, dilengkapi latihan soal, dan beberapa latihan pratik bahasa Inggris dari listening, speaking dan writing, materi tersebut di muat kedalam bentuk teks, gambar, animasi, audio, dan video yang dikemas secara menarik dengan bahasa yang komunikatif sehingga dapat mempermudah anak didik untuk mpengoprasiannya dalam belajar.

Pengembangan ini bertujuan untuk menghasilkan sebuh produk multimedia interaktif berbasis mobile yang layak digunakan pada pelajaran bahasa Inggris. Dengan adanya multimedia interaktif berbasis mobile ini diharapkan pembelajaran lebih intraktif, dan efisien, selain itu juga dapat menambah pengalaman belajar anak didik sehingga pembelajaran lebih komunikatif, menyenangkan serta menarik perhatian anak didik.

\section{METODE}

Pengembangan ini menggunakan model pengembangan (Lee \& Owens, 2004). Adapun penggunaan model pengembangan Lee $\&$ Owens dirasa tepat untuk mengembangkan multimedia pembelajaran 
dikarenakan setiap tahapannya tersusun secara sistematis dan rinci. Dalam metode ini menyediakan desain instruksional dalam mengembangkan angket yang jelas serta mencantumkan respon dari pengalaman pengguna, sehingga produk layak digunakan. Berikut alur tahapan pengembangan Lee \& Owens:

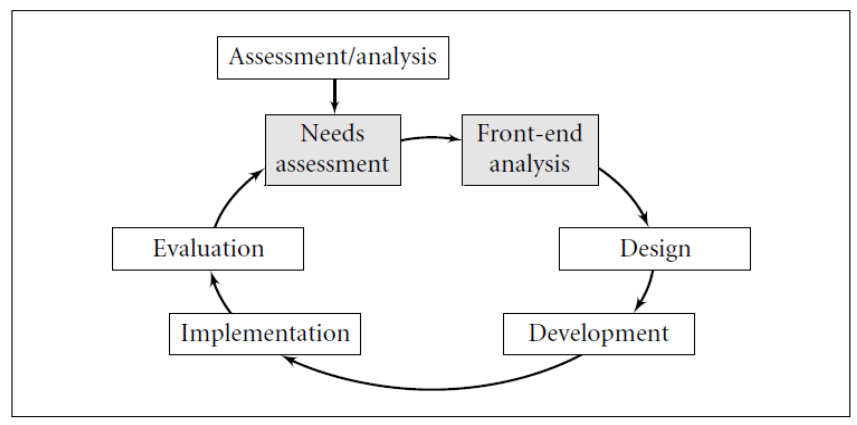

Gambar 1. Alur tahapan pengembangan Lee Owens

Model Lee \& Owen terdapat lima tahapan yaitu Assessment/analysis terdiri dari dua bagian yaitu analisis kebutuhan (need analysis) dan analisis awal akhir (front and analysis), tahap berikutnya desain (design), pengembangan (development), tahap implementasi (implementation), dan terakhir evaluasi (evaluation). Namun dalam pegembangan ini dilaksanakan hanya sampai pada tahap pengembangan (Development).

Tahap assessment/analisis terdiri dari need assessment yaitu analisis kebutuhan dilakukan observasi dan wawancara. Hal tersebut dilakukan untuk mengenal keadaan dan masalah yang terjadi. Front-end analysis untuk mendapatkan data kebutuhan lapangan yang akurat. Dengan beberapa tahapan yang dilakukan diantaranya audience analysis, technology analysis, situation analysis, task analysis, critical analysis,objective analysis, issue analysis, extant-data analysis dan cost analysis.

Tahap desain dilakukan untuk merencanakan produk yang dikembangkan. Lee Owen (2004) menjelaskan beberapa hal yang dilakukan pada tahap desain yaitu jadwal kegiatan (shecdule), tim proyek (project team), spesifikasi media(media specification). Tahap desain ini membuat struktur konten, desain interface, dan beberapa konten audio dan video direncanakan.

Pada tahap pengembangan, multimedia pembelajaran mulai dibuat dari software utama yaitu articulate storyline 3 dan perangkat pendukung lainnya. Konten disusun sesuai dengan kebutuhan, desain interface di rancang semenarik mungkin sehingga dapat menjadi sebuah produk media teknologi digital berupa multimedia interaktif. Pengembangan instrument juga dilakukan untuk menguji kelayakan media pembelajaran pada ahli media dan ahli materi. Uji coba pemanfaatan produk dilakukan terhadap kelompok kecil yaitu siswa SMA kelas XI.

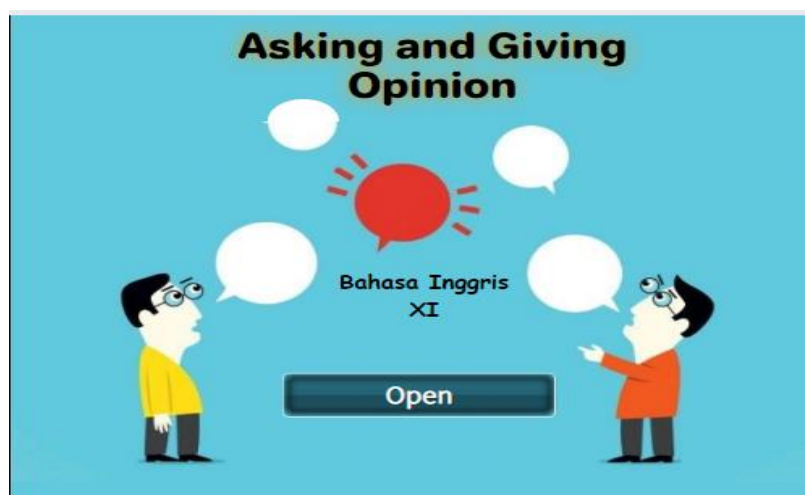

Gambar 2. Tampilan halaman pembuka 
Teknik analisis data menurut (Lee \& Owens, 2004), menggunakan Rating scale yang dipengaruhi oleh total data respon yang didapat dari setiap pernyataan pada angket. Berikut rating scale yang digunakan pada penilaian angket (4) sangat setuju, (2) setuju, (3) tidak setuju (1) sangat tidak setuju.

Penggunaan empat penilaian tersebut digunakan untuk menghilangkan keraguan, biasanya terdapat lima tingkatan yang salah satunya mempunyai arti netral/ragu. Multimedia pembelajaran yang menggunakan konsep (Lee \& Owens, 2004) dapat dikatakan layak dan mendapat respon positif bila data yang didapatkan mayoritas nilai 4 (sangat setuju) hingga 3(setuju). Sedangkan jika mayoritas nilai yang didapatkan (2) tidak setuju hingga (1) sangat tidak setuju maka tidak layak digunakan.

\section{HASIL}

Berdasarkan gambar 2 tampilan halaman pembuka terdapat tombol open, tombol tersebut bertujuan untuk membuka materi pembelajaran. Gambar 3 tampilan halaman menu terdapat tombol home, profil, daftar rujukan, instruction, competensi, materi, quiz, dan chapter. Tombol-tombol tersebut bertujuan untuk membuka halaman yang ingin dikunjungi. Halaman chapter berisikan materi bahasa Inggris dengan penambahan audio pada setiap chapter, dan penambahan video serta ilustrasi gambar sesuai dengan contoh kehidupan nyata.

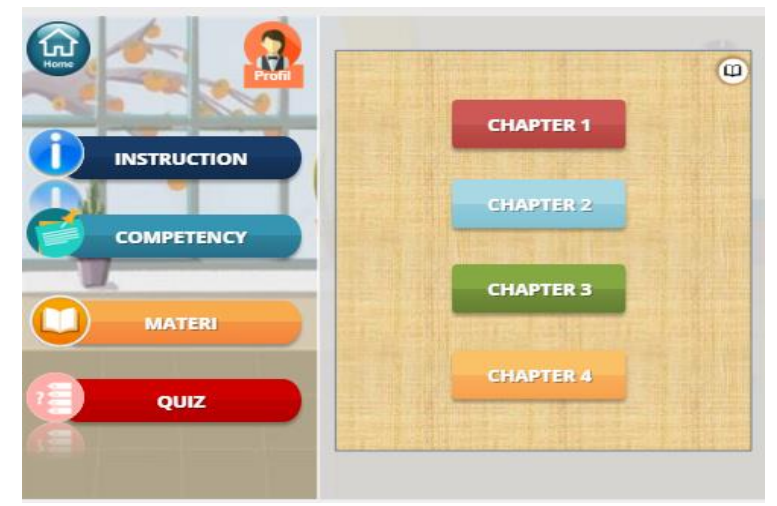

\section{Gambar 3. Tampilan halaman menu}

Berikut hasil tanggapan dari ahli media dan ahli materi pada multimedia interaktif berbasis mobile pada bahasa Inggris disajikan pada grafik 1 dan 2. Berdasarkan grafik 1 hasil tanggapan ahli media dari 41 pernyataan diatas terdapat 40 pernyataan mendapat nilai 4 dan 1 pernyataan mendapat nilai 3 pada Q3. Dari nilai yang didapatkan bahwa multimedia interaktif berbasis mobile mendapatkan respon positif dan layak digunakan. Ahli media juga memberikan saran terhadap multimedia interaktif berbasis mobile ini berupa penambahan petunjuk penggunaan kedalam dua bahasa. Selebihnya ahli media memberikan respon positif terhadap desain interface dari multimedia interaktif berbasis mobile.

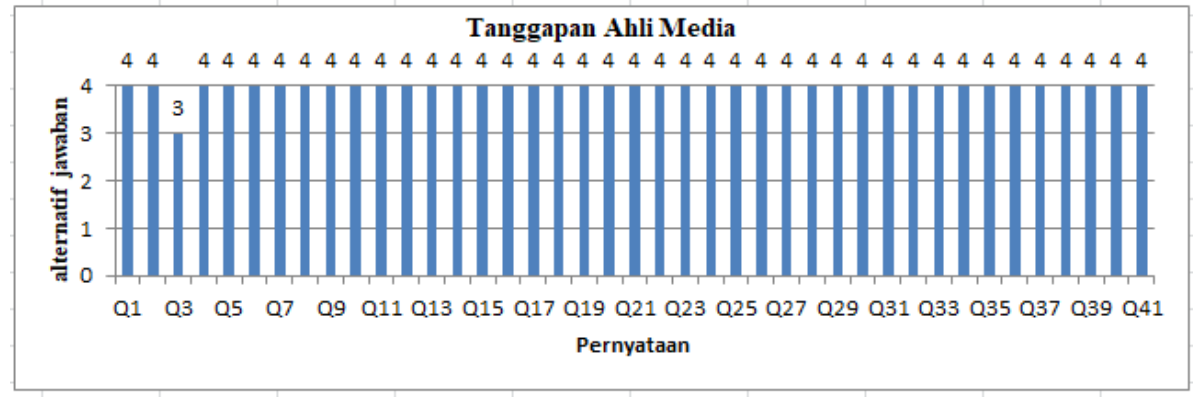

Grafik 1. Tanggapan Ahli Media 
Berdasarkan grafik 1 hasil tanggapan ahli media dari 41 pernyataan diatas terdapat 40 pernyataan mendapat nilai 4 dan 1 pernyataan mendapat nilai 3 pada Q3. Dari nilai yang didapatkan bahwa multimedia interaktif berbasis mobile mendapatkan respon positif dan layak digunakan. Ahli media juga memberikan saran terhadap multimedia interaktif berbasis mobile ini berupa penambahan petunjuk penggunaan kedalam dua bahasa. Selebihnya ahli media memberikan respon positif terhadap desain interface dari multimedia interaktif berbasis mobile pada bahasa Inggris.

Berdasarkan grafik 2 hasil tanggapan ahli materi dari 24 pernyataan diatas terdapat 22 pernyataan mendapat nilai 4 pada dan 2 pernyataan mendapat nilai 3 pada Q21 dan Q22. Dari nilai yang di dapatkan bahwa multimedia interaktif berbasis mobile mendapatkan respon positif dan layak digunakan. Ahli materi memberikan respon bahwa secara keseluruhan multimedia interaktif berbasis mobile bagus. Selain itu ahli materi juga menambahakan saran variasi pada latihan agar tidak terjadi kemonotonan pada pengerjaan latihan soal dan penambahan lebih banyak audio yang bertujuan untuk melatih listening anak didik.

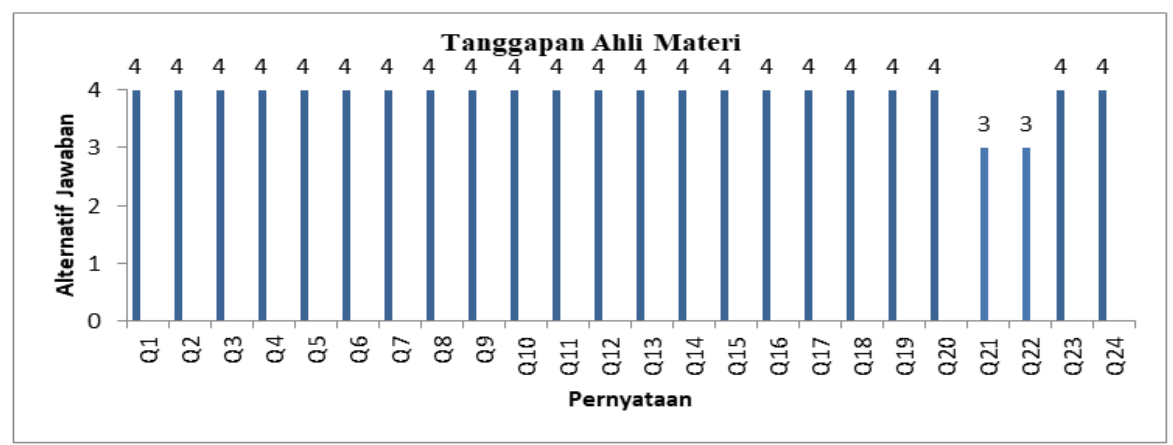

Grafik 2. Tanggapan Ahli Materi

Uji coba kemanfaatan produk multimedia interaktif oleh 3 siswa di dapatkan tanggapan dari responden satu 15 pernyataan mendapat nilai 4. Tanggapan dari responden dua 13 pernyataan mendapat nilai 4 dan 2 pernyataan mendapat nilai 2 pada pernyataan ke Q10 dan pernyataan ke Q13. Tanggapan dari responden tiga 13 pernyataan mendapat nilai 4, 1 pernyataan mendapat nilai 3 pada pernyataan ke Q9 dan 1 pernyataan mendapat nilai 2 pada penyataan ke Q13. Dari hasil tanggapan tersebut dapat dikatakan multimedia interaktif berbasis mobile mendapat respon positif dan layak digunakan.

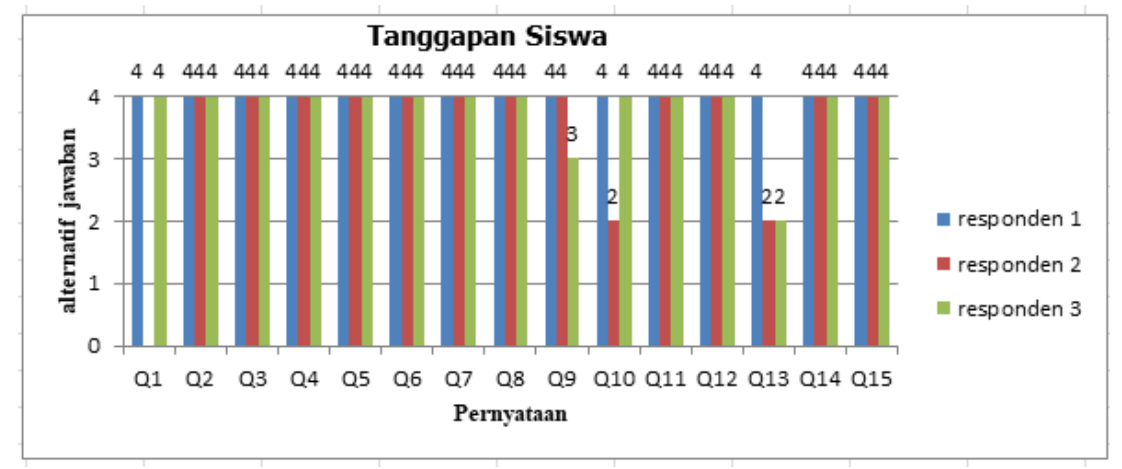

Grafik 3. Tanggapan siswa

\section{PEMBAHASAN}

Dalam pengembangan multimedia interaktif berbasis mobile terdapat beberapa tahapan yang dilakukan sebagai berikut; analisis kebutuhan/need assessment berupa observasi dan wawancara secara langsung. Berdasarkan hasil observasi dan wawancara yang telah dilakukan ditemukan 
kendala dalam proses pembelajaran tersebut terkait penggunaan media dalam pembelajaran khususnya pada bahasa Inggris, untuk kemudian diberikan solusi dalam permasalahan tersebut yakni dengan digunakannya multimedia interaktif yang akan dipadukan dengan teknologi terkini berupa mobile learning.

Front-end analysis bertujuan untuk memperoleh data kebutuhan lapangan yang lebih akurat. Pada tahapan ini dilakukan penganalisisan karakteristik anak didik, pengecekan fasilitas yang tersedia serta keadaan di SMA Ahmad Yani Ngebruk yang bertujuan untuk memperoleh informasi sebagai gambaran untuk pengembangan yang akan dilakukan sehingga mempermudah menentukan tujuan pembelajaran dan mengatisipasi kendala pada saat media digunakan. Penggunaan multimedia interaktif dalam pembelajaran seperti pada penelitian Radityan et al., (2016) menujukan bahwa penggunaan multimedia interaktif sangat membantu guru dan anak didik pada saat proses pembelajaran. penelitian yang dilakukan oleh Warsita (2018), terkait penggunaan mobile learning pada pembelajaran sangat efektif dan inovatif sehingga memotivasi semangat belajar anak didik dan guru. Di SMA Ahmad Yani Ngebruk setiap anak didik memiliki perangkat smatphone, sehingga dapat dipastikan akses anak didik menggunakan multimedia interaktif berbasis mobile dapat terfasilitasi.

Design yang dihasilkan berupa multimedia pembelajaran yang dioprasikan melalui mobile device atau smartphone. penggunaan multimedia lebih terfokus pada interaktivitas antara pengguna dengan media (Munir, 2012). Penggunaan mobile learning menjadikan pembelajaran berjalan secara efisien tanpa ada batasan waktu dan ruang(Godwin-Jones, 2011). Maka produk yang dikembangkan berupa multimedia interakif berbasis mobile. Berdasarkan penelitian (Rorita et al., 2018) pembelajaran menggunakan mobile lebih efisien dikarenakan tidak membutuhkan ruang penyimpanan data yang besar dan dapat dimanfaatkan dalam kegiatan belajar mandiri atau pun belajar di kelas. Multimedia interaktif berbasis mobile yang dikembangkan berisikan materi bahasa Inggris yang meliputi latihan grammar, vocabulary dan skill. Disajikan secara audio berupa cara pengucapan yang benar yang akan melatih listening siswa, visual melalui teks penyusunan penulisan yang benar, dan gambar, video, animasi, ilustrasi sebagai contoh kehidupan nyata. Disajikan pula latihan soal dengan penilaian bertujuan agar anak didik dapat belajar berulang sampai mencapai nilai yang diinginkan.

Sesudah tahap desain selesai dirancang kemudian dilakukan tahap development/pengembangan. Pada tahap pengembangan software utama yang digunakan untuk mengembangkan multimedia interaktif ini adalah software articulate storyline 3 , konten materi disusun berdasarkan kebutuhan pembelajaran, desain interface disusun semudah dan semenarik mungkin agar pengguna dalam mengoprasikan multimedia interaktif tidak mengalami kesulitan dan kejenuhan dalam proses belajar, setelah semua konten materi dan desain interface disusun menjadi satu, langkah selanjutnya file dirender menajadi file .apk, proses render menggunakan software java dan website 2 apk Builder. Setelah aplikasi multimedia interaktif selesai di kembangkan kemudian di reviuw kelayakannya oleh ahli media, ahli materi dan di ujicoba kan kemanfaatan produk multimedia interaktif berbasis mobile pada anak didik. Seperti penelitian yang dilakukan oleh (Zulham \& Sulisworo, 2017) yang menghasilkan produk multimedia interaktif berbasis mobile yang layak digunakan.

Berdasarkan tanggapan para ahli, multimedia interaktif berbasis mobile yang dikembangkan secara keseluruhan bagus mulai dari tampilan desain interface sampai konten yang digunakan sesuai materi. Tanggapan dari ahli media di dapatkan 40 pernyataan dengan nilai 4 dan 1 pernyataan dengan nilai 3. Dari hasil tanggapan tersebut multimedia interaktif berbasis mobile mendapatkan niali positif dan layak digunakan. Ahli media juga menambahakan saran berupa penambahan 
petunjuk penggunaan dengan dua bahasa yakni bahasa Indonesia dan bahasa Inggris bertujuan agar anak didik tahu apa yang harus dilakukan dan dikerjakan terlebih dahulu. Hasil tanggapan ahli materi di dapatkan 22 pernyataan dengan nilai 4 dan 2 pernyataan dengan nilai 3 . Dari hasil tanggapan tersebut dapat dikatakan multimedia interaktif berbasis mobile mendapakan respon positif dan layak digunakan. Ahli materi juga menambhakan saran berupa penambahan variasi pada latihan agar tidak terjadi kemonotonan pada pengerjaan latihan soal dan penambahan lebih banyak audio yang bertujuan untuk melatih listening siswa.

Sedangkan untuk uji coba kemanfaatan produk multimedia interaktif oleh 3 siswa di dapatkan tanggapan dari responden satu 15 pernyataan mendapat nilai 4. Tanggapan dari responden dua 13 pernyataan mendapat nilai 4 dan 2 pernyataan mendapat nilai 2. Tanggapan dari responden tiga 13 pernyataan mendapat nilai 4, 1 pernyataan mendapat nilai 3 dan 1 pernyataan mendapat nilai 2 . Dari hasil tanggapan tersebut dapat dikatakan multimedia interaktif berbasis mobile mendapat respon positif dan layak digunakan.

Pengembangan multimedia interaktif merupakan pendekatan kontekstual yang berpusat pada berbagai aspek yang mendukung proses pembelajaran, lingkungan belajar, kelas, laboratorium, dan perangkat teknologi yang menjadikan pembelajaran efektif dan menyenangkan (Munir, 2012)

Multimedia interaktif merupakan lingkungan belajar yang berbasis teknologi software computer untuk menangani masalah-masalah belajar anak didik (Sudathra, 2009). Multimedia interaktif dapat digunakan dalam berbagai aplikasi instruksional, yang digunakan untuk menjelaskan suatu konsep tertentu hingga fenomena ilmiah. Berdasarkan penelitian yang dilakukan (Radityan, 2016) manfaat multimedia interaktif dapat mempermudah anak didik dalam memahami materimateri yang bersifat abstrak, menarik minat anak didik dalam belajar, dan mudah dioperasikan.

Pada multimedia interaktif yang dikembangkan ini terdapat beberapa kelebihan yang menjadikan multimedia interaktif berbeda dari penelitian sebelumnya. Multimedia interaktif ini memiliki kelebihan yang penggunaannya memanfaatkan sebuah teknologi piranti gerak (mobile device) yang memungkinkan terjadinya kemudahan dalam pembelajaran terutama dalam pembelajaran secara mandiri. Hal ini juga di jelaskan dari penelitian sebelumnya yaitu pengembangan multimedia interaktif berbasis Android yang memiliki kelebihan dapat digunakan diamana saja dan kapan saja (Rahardjo et al., 2019). Penggunaan mobile device pada saat ini bukanlah sesuatu yang baru akan tetapi sudah menjadi bagian utama dari kehidupan mulai dari berbagai kalangan dan berbagai lembaga termasuk lembaga pendidikan (Koderi, 2015).

Pengembangan multimedia interaktif yang dikembangkan ini dapat digunakan secara berkelompok maupun secara mandiri. Penggunaan multimedia interaktif berbasis mobile yang digunakan secara berkelompok mengikuti arahan dari guru sedangkan untuk penggunaan secara mandiri dapat dilakukan oleh anak didik dimanapun dan kapanpun tanpa harus menunggu arahan dari guru sehingga anak didik dapat mempelajari materi tersebut berulang-ulang sampai anak didik dirasa sudah paham mengenai materi tersebut.

Penggunaan multimedia interaktif berbasis mobile merupakan sebuah alternative yang dapat digunakan sebagai suplemen tambahan dalam proses pembelajaran bahasa Inggris. Berdasarkan penelitian yan dilakukan (Saifudin et al., 2020) penggunaan multimedia interaktif berbasis mobile ini dirasa mampu untuk memfasilitasi para pebelajar tanpa ada batasan waktu dan ruang (Surahman, 2017). Selain itu untuk mewujukan pembelajaran yang lebih masif dan sesuai dengan kebutuhan serta karakteristik pengguna, maka sebaiknya media mobile learning dirancang adaptif dan terintegrasi dengan layanan pembelajaran online (Surahman \& Alfindasari, 2018; Surahman, 2019)

Dari yang telah dijelaskan sebelumnya dengan adanya mobile learning yang memiliki komputasi dan konektivitas yang lebih canggih menjadikan pembelajaran melalui aplikasi mobile 
dapat meningkatkan minat dan pengalaman pebelajar (Mamat \& Azmat, 2013). Mobile learning merupakan bagian dari e-learning yang yang berisikan conten education yang bersifat fleksible dapat digunakan dan diakses kapan saja dan dimana saja sehingga dapat mengatasi keterbatasan waktu, ruang, dan indra (Setyadi, 2017). Berdasarkan penelitian sebelumnya multimedia interaktif berbasis mobile dapat digunakan dalam bentuk online delivery ataupun offline delivery (Sudathra, 2009).

Multimedia interaktif berbasis mobile ini mencakup segala kebutuhan pengguna dalam mata pelajaran bahasa Inggris, tampilan dalam aplikasi multimedia interaktif berbasis mobile ini di buat dengan menarik dan sangat user friendly yang dapat membantu anak didik dalam pemakaian multimedia interaktif berbasis mobile. Dalam produk multimedia interaktif berbasis mobile yang dikembangkan ini dilengkapi petunjuk penggunaan aplikasi, konten yang tedapat dalam multimedia interaktif berbasis mobile pun beragam terdapat konten materi dalam bentuk gambar, teks, audio, animasi, dan video yang dimana multimedia interaktif berbasis mobile ini telah sesuai dengan kebutuhan pembelajaran bahasa Inggris.

Tujuan multimedia interaktif dalam pendidikan adalah untuk menstimulasikan lebih dekat kondisi pembelajaran di dunia nyata dan sekaligus sebagai pengalaman multisensory anak didik. Sistem multimedia dapat terdiri dari kombinasi media tradisional atau mungkin menggabungkan media teknologi sebagai perangkat tampilan teks, gambar, grafik, suara dan video (Heinich et al., 2002)

Pada pengembangan multimedia interaktif sebelumnya yang pernah di kembangkan oleh beberapa pengembang terkait pengembangan multimedia interaktif lebih sering diterapkan pada perangkat komputer yang menghasilkan sebuh multimedia interaktif yang layak digunakan pada pembelajaran yang bersifat konseptual, teorial maupun pembelajaran yang bersifat praktik(Munir, 2020). Seperti yang telah dipaparkan pada penelitian sebelumnya (Yusuf et al., 2017) penggunaan multimedia interaktif sangat efektif digunakan dalam pembelajaran. Mayoritas berdasarkan hasil penelitian sebelumnya yaitu pengembangan multimedia pembelajaran bagus untuk digunakan dalam pembelajaran.

Pada pengembangan pengembangan multimedia interaktif dikembangkan dengan memanfaatkan perangkat mobile yang memiliki beberapa kelebihan yang tidak dimiliki oleh perangkat komputer, yaitu lebih ramah tempat, dapat menghemat waktu, tidak dibutukannya sebuah perangkat kabel yang terpasang dan dapat digunakan dimanapun kapan pun(Crompton \& Burke, 2018). Berdasarkan hasil penelitian sebelummnya dapat disimpulkan bahwa multimedia interaktif berbasis mobile layak digunakan sebagai media untuk membantu guru dan anak didik dalam proses belajar bahasa Inggris.

\section{SIMPULAN}

Pengembangan multimedia interaktif berbasis mobile pada bahasa Inggris merupakan sebuah alternatif dan solusi untuk melengkapi kekurangan pada pembelajaran bahasa Inggris di SMA Ahmad Yani Ngebruk. Multimedia interaktif ini digunakan sebagai supplemen tambahan dalam pembelajaran sehingga anak didik dapat mengakses materi dimanapun dan kapanpun tanpa terbatas waktu dan ruang. Didapatkan tanggapan dari para ahli dan uji kemanfaatan produk oleh anak didik bahwa multimedia interaktif berbasis mobile layak digunakan.

\section{DAFTAR RUJUKAN}

Arief, S. (2009). Media pendidikan, pengertian, pengembangan, dan pemanfaatannya. In Jakarta: PT. Rajagrafindo Persada.

Azhar, N., \& Ardi, M. (2008). Uji validitas dan reliabilitas paket multimedia interaktif. Ilmu Komputer, 1-15.

Crompton, H., \& Burke, D. (2018). The use of mobile learning in higher education: A systematic 
review. Computers \& Education, 123, 53-64.

Darmawan, D. (2014). Inovasi pendidikan: pendekatan praktik teknologi multimedia dan pembelajaran online. PT Remaja Rosdakarya.

Georgiev, T., Georgieva, E., \& Smrikarov, A. (2004). M-learning-a New Stage of -Learning. International Conference on Computer Systems and Technologies-CompSysTech, 4(28), 1-4.

Godwin-Jones, R. (2011). Emerging technologies: Mobile apps for language learning. Language Learning and Technology, 15(2), 2-11.

Heinich, R., Molenda, M., Russel, J. D., \& Smaldino, S. E. (2002). Instructional media and technology for learning. Pearson Education Ltd.

Husamah. (2013). Pembelajaran Luar Kelas Outdoor Learning. In Buku Ajar.

Koderi, R. (2015). Pengembangan ICT dalam Pembelajaran Bahasa Arab. Program Studi Teknologi Pendidikan Universitas Sebelas Maret, November, 102-114.

Lee, W. W., \& Owens, D. L. (2004). Multimedia-based instructional design: computer-based training, web-based training, distance broadcast training, performance-based solutions. John Wiley \& Sons.

Littlewood, W., \& William, L. (1984). Foreign and second language learning: Language acquisition research and its implications for the classroom. Cambridge University Press.

Mamat, K., \& Azmat, F. (2013). Mobile Learning Application for Basic Router and Switch Configuration on Android Platform. Procedia - Social and Behavioral Sciences, 90(InCULT 2012), 235-244.

Munir. (2020). Multimedia Konsep \& Aplikasi Dalam Pendidikan. In Antimicrobial agents and chemotherapy (Vol. 58, Issue 12).

Munir, P. D. (2012). Multimedia konsep \& aplikasi dalam pendidikan.

Radityan, F. T., Kuntadi, I., \& Komaro, M. (2016). Pengaruh Multimedia Interaktif Terhadap Hasil Belajar Siswa Pada Kompetensi Perbaikan Differential. Journal of Mechanical Engineering Education, 1(2), 239.

Rahardjo, T., Degeng, N., \& Soepriyanto, Y. (2019). Pengembangan Multimedia Interaktif Mobile Learning Berbasis Anrdroid Aksara Jawa Kelas X Smk Negeri 5 Malang. Jurnal Kajian Teknologi Pendidikan, 2(3), 195-202.

Rorita, M., Ulfa, S., \& Wedi, A. (2018). Pengembangan Multimedia Interaktif Berbasis Mobile Learning Pokok Bahasan Perkembangan Teori Atom Mata Pelajaran Kimia Kelas X SMA Panjura Malang. JINOTEP (Jurnal Inovasi Dan Teknologi Pembelajaran): Kajian Dan Riset Dalam Teknologi Pembelajaran, 4(2), 70-75.

Saifudin, M., Susilaningsih, S., \& Wedi, A. (2020). Pengembangan Multimedia Interaktif Materi Sumber Energi untuk Memudahkan Belajar Siswa SD. JKTP: Jurnal Kajian Teknologi Pendidikan, 3(1), 68-77.

Sanaky, H. A. H. (2013). Media pembelajaran interaktif-inovatif. Yogyakarta: Kaukaba Dipantara.

Setyadi, D. (2017). Pengembangan Mobile Learning Berbasis Android Sebagai Sarana Berlatih Mengerjakan Soal Matematika. Satya Widya, 33(2), 87-92.

Sihkabuden. (2015).Media Pembelajaran. Malang: Departemen Nasional Universitas Negeri Malang Fakultas Ilmu Pendidikan

Sudatha, I. G. W. (2009). Desain Multimedia Pembelajaran I Gde Wawan Sudatha I Made Tegeh Jurusan Teknologi Pendidikan Universitas Pendidikan Ganesha.

Surahman, E., \& Surjono, H. D. (2017). Pengembangan adaptive mobile learning pada mata pelajaran biologi SMA sebagai upaya mendukung proses blended learning. Jurnal Inovasi 
Teknologi Pendidikan, 4(1), 26-37.

Surahman, E., \& Alfindasari, D. (2017, September). Developing adaptive mobile learning with the principle of coherence Mayer on biology subjects of high school to support the open and distance education. In 3rd International Conference on Education and Training (ICET 2017) (pp. 184-190). Atlantis Press.

Surahman, E. (2019). Integrated mobile learning system (imoles) sebagai upaya mewujudkan masyarakat pebelajar unggul era digital. JINOTEP (Jurnal Inovasi Dan Teknologi Pembelajaran) Kajian Dan Riset Dalam Teknologi Pembelajaran, 5(2), 50-56.

Warsita, B. (2018). Mobile Learning Sebagai Model Pembelajaran Yang Efektif Dan Inovatif. Jurnal Teknodik, 14(1), 062.

Yusuf, M. F., Toenlioe, A. J. E., \& Wedi, A. (2017). Pengembangan Multimedia Pembelajaran Interaktif IPA Materi Atmosfer Bumi Kelas VIII SMPN 3 Tulungagung. Edcomtech Jurnal Kajian Teknologi Pendidikan, 2(1), 37-40.

Zulham, M., \& Sulisworo, D. (2017). Pengembangan Multimedia Interaktif Berbasis Mobile dengan Pendekatan Kontekstual pada Materi Gaya. Jurnal Penelitian Pembelajaran Fisika, 7(2), 132-141. 